\title{
Short communication: Effect of stirring operations on changes in physical and rheological properties of nonfat yogurts during storage
}

\author{
V. Guénard-Lampron, ${ }^{1,2,3} \odot$ D. St-Gelais, ${ }^{1,2,3}$ S. Villeneuve, ${ }^{2,3}$ and S. L. Turgeon ${ }^{1,2 *}$ (]) \\ ${ }^{1}$ Dairy Science and Technology Research Centre (STELA), Université Laval, Quebec City, QC, G1V 0A6, Canada \\ ${ }^{2}$ Institute of Nutrition and Functional Foods (INAF), Université Laval, Quebec City, QC, G1V 0A6, Canada \\ ${ }^{3}$ Saint-Hyacinthe Research and Development Centre, Agriculture and Agri-Food Canada, 3600 Casavant Boulevard West, Saint-Hyacinthe, \\ QC, J2S 8E3, Canada
}

\begin{abstract}
The rheological and physical properties of stirred yogurt depend on several parameters, including the mechanical stress caused by stirring, smoothing, and cooling conditions (duration, intensity, or temperature). However, the literature reports little information about the effects of mechanical stress from all of the stirring operations on changes in yogurt properties during storage. The aim of this study was to determine, by means of a technical scale unit, the combined effects of stirring in the yogurt vat, smoothing, and cooling on changes in the rheological properties of nonfat yogurt during storage at $4^{\circ} \mathrm{C}$. The yogurt was standardized to $14 \%$ total solids, $0 \%$ fat, and $4 \%$ protein, and was stirred with a technical scale unit using 2 stirring durations (5 min or $10 \mathrm{~min}$ ), 2 types of cooling systems (plate or tubular heat exchanger), and 2 smoothing temperatures $\left(38^{\circ} \mathrm{C}\right.$ for yogurts smoothed before cooling or $20^{\circ} \mathrm{C}$ for yogurts smoothed after cooling). All yogurts were stored for $22 \mathrm{~d}$ at $4^{\circ} \mathrm{C}$, and we determined the combined effect of the stirring operations on changes in syneresis, apparent viscosity, firmness, consistency, and flow time. During storage, post-acidification was the same for all stirred yogurts and involved restructuring of the protein network, which resulted in an increase in all properties except syneresis, which decreased. The combined stirring operations did not modify changes in syneresis during yogurt storage but did affect flow time, viscosity, consistency, and firmness. Changes in flow time depended on smoothing temperature, and viscosity and consistency depended on the cooling system used. Firmness was the property most affected by all combined stirring operations during storage. Therefore, the technical scale unit was effective for quantifying the combined effects of stirring, smoothing, and cooling on
\end{abstract}

Received February 5, 2019.

Accepted August 15, 2019.

*Corresponding author: sylvie.turgeon@fsaa.ulaval.ca changes in yogurt properties during storage. This study also confirmed that the restructuring of stirred yogurt depended on the mechanical stress that occurred during the stirring process.

Key words: rebodying, mechanical post-processing, fermented milk, rheological property, restructuring

\section{Short Communication}

Yogurts are very popular worldwide, and a wide variety of yogurt products (such as set, stirred, Greek, frozen, and drinking) are available. Despite yogurt's popularity, however, texture defects are still problematic, especially for stirred yogurt (Sodini et al., 2004; Lee and Lucey, 2010). Stirred yogurt is affected greatly by the shear of the stirring, smoothing, and cooling operations performed after fermentation in the yogurt vat (Tamime and Robinson, 1999). During these operations, the protein network is broken into gel particles of different sizes, which can result in a loss of viscosity and firmness and an increase in syneresis (Zoon, 2003; Renan et al., 2009; Guénard-Lampron et al., 2019).

The literature reports that during the storage of stirred yogurt at $4^{\circ} \mathrm{C}$, post-acidification increases the size of casein particles, allows the formation of new interactions (mostly hydrophobic and electrostatic) between proteins, and contributes to the partial restructuring (rebodying) of the protein network (Lucey, 2004; Robinson et al., 2007; Renan et al., 2008; Casarotti et al., 2014). The protein network becomes more homogeneous, dense, and stable, so that viscosity and firmness increase and syneresis decreases (Puvanenthiran et al., 2002; Serra et al., 2009). Network rebodying is dependent on all interactions between proteins created during the fermentation step, and those interactions are broken during the stirring operations (Arshad et al., 1993; Lee and Lucey, 2006; Renan et al., 2009). However, most studies in the literature were carried out on a laboratory scale, and the yogurts were often stirred using spoons, stirring rods, or blenders, none of which are representative of industrial production conditions. 
Mokoonlall et al. (2016) used data available in the literature to estimate the maximum and minimum changes in rheological properties of stirred yogurt and demonstrate the important effects of post-processing operations. Recently, the importance of the sequence and combination of stirring operations (stirring, pumping, smoothing, and cooling) on the physical and rheological properties of yogurt was shown using a technical scale unit (Guénard-Lampron et al., 2019). However, the effect of the combined operations on property changes in the yogurt during storage was not evaluated. The operational parameters (duration, speed, intensity, or temperature) of the stirring process could modify the rebodying of the protein network and change the rheological properties of the yogurts during storage. The aim of this study was to monitor the changes in syneresis, viscosity, firmness, consistency, and flow time in a nonfat yogurt stored for $22 \mathrm{~d}$ that had been stirred using a technical scale unit. We also determined the combined effect of stirring duration ( 5 or $10 \mathrm{~min}$ ), smoothing temperature $\left(38\right.$ or $\left.20^{\circ} \mathrm{C}\right)$, and cooling system (plate or tubular heat exchanger).

The nonfat stirred yogurts $(0 \%$ fat, $14 \%$ total solids, and $4 \%$ total proteins with a casein-whey protein ratio of 2.8) used in this study were the same as those produced by Guénard-Lampron et al. (2019) with the 2 configurations of the technical scale unit. Briefly, stirring in the yogurt vats was performed for 5 min (St5) or $10 \mathrm{~min}$ (St10) at a speed of $30 \mathrm{rpm}$. After stirring, the speed of the stirrer was reduced and maintained at $15 \mathrm{rpm}$, and pumping of the yogurt into the piping began. In the sequence of operations for configuration 1 , smoothing (425- $\mu \mathrm{m}$ filter nozzle) came before cooling and was therefore performed at a temperature of approximately $38^{\circ} \mathrm{C}(\mathbf{S m} 38)$. Then, the yogurt was directed to either a plate heat exchanger (PHX; type A3-HBM; Alfa Laval, Lund, Sweden) or a tubular heat exchanger (THX; PG7757/84; Sepak Industries Pty Ltd., Sydney, Australia) for cooling to $20^{\circ} \mathrm{C}$. The sequence of operations for configuration 2 was presmoothing (1.4 mm filter nozzle) followed by cooling with 1 of the 2 cooling systems (PHX or THX), and then smoothing at $20^{\circ} \mathrm{C}(\mathbf{S m 2 0})$. The technical scale unit was therefore used to investigate 2 stirring durations (St5 and St10), 2 smoothing temperatures (Sm38 and Sm20), and 2 cooling systems (PHX and THX). The 8 operational combinations were St5-PHX-Sm38, St10-PHX-Sm38, St5-THX-Sm38, St10-THX-Sm38, St5-PHX-Sm20, St10-PHX-Sm20, St5-THX-Sm20, and St10-THX-Sm20.

Guénard-Lampron et al. (2019) collected stirred yogurts at the outlet of the technical scale unit in $175-\mathrm{mL}$ containers for all analyses except the posthumus funnel analysis, for which yogurt samples were collected in 500
mL containers (Plastipak; GenPak, Boucherville, QC, Canada). All yogurts were stored in a cold room at $4^{\circ} \mathrm{C}$, and containers were selected randomly for analysis after 3, 13, and 22 d. Composition, microbial counts, syneresis, firmness, apparent viscosity, Bostwick consistency, and flow time were determined as described by Guénard-Lampron et al. (2019).

We determined changes in syneresis, firmness, viscosity, distance traveled (consistency), and flow time for the stirred yogurts by subtracting, for each day of storage $(1,3,13$, and $22 \mathrm{~d})$, the value obtained on $\mathrm{d} 1$ by Guénard-Lampron et al. (2019) to obtain a $\Delta$ value. We performed these calculations for each of the 3 replicates of all stirred yogurts and used them to perform the statistical analyses. The 8 combinations of operating parameters (consisting of 2 stirring durations, 2 smoothing temperatures, and 2 cooling systems) were randomized and repeated 3 times. We used a split-plot statistical design to compare the raw values for $\mathrm{pH}$ and bacterial population, as well as the $\Delta$ values for each property. Operating parameters were the main factor, and the number of days of storage was the subplot factor. The statistical analyses were performed with the GLM (general linear model) procedure of SAS (version 2.5.14; SAS Institute Inc., Cary, NC), and tested significant differences at $P \leq 0.05$.

The values for each property after $1 \mathrm{~d}$ of storage have been reported by Guénard-Lampron et al. (2019). Supplemental Table S1 (https://doi.org/10.3168/jds .2019-16434) shows the mean values for all yogurt produced and analyzed after $1 \mathrm{~d}$. As reported by GuénardLampron et al. (2019), all yogurts had the same composition (fat: $0.17 \pm 0.03 \%$; total solids: $14.0 \pm 0.1 \%$; true proteins: $4.2 \pm 0.1 \%$; caseins: $3.10 \pm 0.02 \%$; whey proteins: $1.11 \pm 0.03 \%$; casein-whey protein ratio: 2.79 $\pm 0.03)$. No significant effect $(P>0.05)$ of operations (stirring, smoothing, and cooling) was observed for $\mathrm{pH}$ or bacterial populations. Only a significant effect $(P \leq$ 0.05 ) of storage time was observed. A significant decrease in $\mathrm{pH}$ was observed in all yogurts over the first $13 \mathrm{~d}$ (4.36 to $4.17 \pm 0.01)$, after which the $\mathrm{pH}$ remained stable. The populations of lactobacilli $(8.27 \pm 0.05 \mathrm{log}$ $\mathrm{cfu} / \mathrm{mL})$ and streptococci $(8.51 \pm 0.05 \mathrm{log} \mathrm{cfu} / \mathrm{mL})$ remained relatively stable for the first $13 \mathrm{~d}$ of storage and then decreased significantly, to 7.87 and $8.34 \pm 0.05 \log$ $\mathrm{cfu} / \mathrm{mL}$ on $\mathrm{d} 22$, respectively.

Table 1 shows the effect of the 8 combinations of operations on the change in physical and rheological properties after $22 \mathrm{~d}$ of storage. We observed no significant effect $(P>0.05)$ of the operations (stirring, smoothing, and cooling) for syneresis, but a significant effect $(P$ $\leq 0.05$ ) of storage time. Regardless of the combined operations used to stir the yogurts, syneresis decreased significantly during the first $13 \mathrm{~d}$ of storage (0 to $1.6 \pm$ 
Table 1. Effect of the 8 combinations of operations ${ }^{1}$ on the change in physical and rheological properties after $22 \mathrm{~d}$ of storage

\begin{tabular}{|c|c|c|c|c|c|c|c|c|}
\hline \multirow[b]{3}{*}{ Property } & \multicolumn{4}{|c|}{ Sm38 } & \multicolumn{4}{|c|}{ Sm20 } \\
\hline & \multicolumn{2}{|c|}{ PHX } & \multicolumn{2}{|c|}{ THX } & \multicolumn{2}{|c|}{ PHX } & \multicolumn{2}{|c|}{ THX } \\
\hline & St5 & St10 & St5 & St10 & St5 & St10 & St5 & St10 \\
\hline Syneresis & 0 & 0 & 0 & 0 & 0 & 0 & 0 & 0 \\
\hline Flow time & ++ & ++ & ++ & ++ & + & + & + & + \\
\hline Viscosity & + & + & ++ & ++ & + & + & ++ & ++ \\
\hline Consistency & + & + & ++ & ++ & + & + & ++ & ++ \\
\hline Firmness & ++ & ++ & ++ & + & ++ & ++ & + & +++ \\
\hline
\end{tabular}

${ }^{1} \mathrm{Sm} 38=$ smoothing before cooling at $38^{\circ} \mathrm{C}$; Sm20 = smoothing after cooling at $20^{\circ} \mathrm{C}$; PHX = plate heat exchanger; THX $=$ tubular heat exchanger; St5 = stirring for $5 \mathrm{~min}$; St10 $=$ stirring for $10 \mathrm{~min}$. For each property, the effect of the combinations of operations is indicated as follows: $0=$ no effect; $+=$ operations promoted a small but significant increase $;++$ and $+++=$ operations promoted a more important significant increase.

$0.3 \%$ ) and stayed relatively constant thereafter (results not shown). Unlike syneresis, the increases in flow time, viscosity, consistency and firmness during storage were significantly $(P \leq 0.05)$ modified by one or more of the operations used to stir the yogurts (Table 1). Flow time was modified by the smoothing temperature; viscosity and consistency were mostly influenced by the cooling system. Firmness was the property affected most by all of the stirring operations. The increase in flow time was significantly higher after $3 \mathrm{~d}$ and up to $22 \mathrm{~d}$, and the changes in flow time were significantly higher for Sm38 $(+39.9 \pm 2.5 \mathrm{~min} ; 22 \mathrm{~d})$ compared to $\mathrm{Sm} 20(+17.7 \pm$ $2.2 \mathrm{~min} ; 22 \mathrm{~d}$ ). Changes in viscosity were higher after $3 \mathrm{~d}$ and up to $22 \mathrm{~d}$ when the yogurts were cooled using the THX $(+0.39 \pm 0.04 \mathrm{~Pa} \cdot \mathrm{s} ; 22 \mathrm{~d})$ compared to the PHX $(+0.09 \pm 0.04 \mathrm{~Pa} \cdot \mathrm{s} ; 22 \mathrm{~d})$. For consistency values, no significant difference was observed up to 13 d. At 22 d, THX yogurts showed higher increase in consistency, observed by a higher decrease in distance traveled $(-1.2 \pm 0.1 \mathrm{~cm})$ compared with PHX yogurts $(-0.6 \pm 0.1 \mathrm{~cm})$.

The increase in firmness during storage was significantly different at $22 \mathrm{~d}$ depending on the smoothing temperature, stirring duration, and cooling system used (Table 1 and Figure 1). We observed an effect of stirring duration (St5 or St10) when the THX system was used, and this effect also depended on smoothing temperature. When smoothing at $38^{\circ} \mathrm{C}$ (Figure $1 \mathrm{~A}$ ) was used, firmness was lower for the yogurts stirred for $10 \mathrm{~min}$ than for those stirred for $5 \mathrm{~min}$. However, we observed an opposite trend for smoothing at $20^{\circ} \mathrm{C}$ (Figure $1 \mathrm{~B}$ ). In that case, firmness was significantly higher when the yogurts were stirred for $10 \mathrm{~min}$ instead of $5 \mathrm{~min}$. Firmness was also affected by the cooling system when the yogurts were stirred for 10 min (St10) and smoothed at $38^{\circ} \mathrm{C}$ (Figure 1A): firmness values were higher with the PHX system than with the THX system. In addition, when THX and St10 operations were used, firmness was lower when yogurts were smoothed at $38^{\circ} \mathrm{C}$ (Figure $1 \mathrm{~A}$ ) than when they were smoothed at $20^{\circ} \mathrm{C}$ (Figure 1B).

The restructuring of the protein network that occurs during yogurt storage depends on the entire shear history during stirring operations (Fangary et al., 1999; Sodini et al., 2004; Weidendorfer et al., 2008; GuénardLampron et al., 2019). In this study, we used 8 different combined stirring operations. The effects of these combined operations on the physical and rheological properties observed on the first day of storage, just after the yogurts had been stirred (Guénard-Lampron et al., 2019), were different from the effects observed in the present study during yogurt storage. The changes in the rheological and physical properties of stirred yogurts during storage are even more important than after $1 \mathrm{~d}$ of storage, because these changes occur at the time of retail sale and consumption. After $1 \mathrm{~d}$ of storage, Guénard-Lampron et al. (2019) observed lower syneresis when the PHX system was used to cool the yogurt instead of the THX system. However, during yogurt storage, this difference disappeared: changes in syneresis were similar regardless of the combined stirring operations used. An opposite trend was observed with viscosity: all combined stirring operations had no effect on viscosity at d 1 (Guénard-Lampron et al., 2019), but the increase in viscosity after $13 \mathrm{~d}$ of storage was lower when the PHX system was used (results not shown). Guénard-Lampron et al. (2019) also observed lower consistency (distance traveled) and lower firmness when PHX was used instead of THX. In the present study, the increases in firmness and in consistency (decrease in distance traveled) were lower with the PHX system but only at $22 \mathrm{~d}$ of storage. In addition, some operations, such as stirring duration, which had no effect after $1 \mathrm{~d}$ of storage (Guénard-Lampron et al., 2019), appeared to induce changes in firmness after $22 \mathrm{~d}$ of storage. These results indicate that the restructuring 
of the protein network and the changes in rheological and physical properties during storage depended on the mechanical stress of the combined stirring operations. As explained by Mokoonlall et al. (2016), the mechanical stress of the stirring operations implies structural losses that depend on the design and configuration of the unit operations. In addition, the changes in rheological properties during storage could be explained by the rearrangement of gel particles. These rearrangements could be observed at different structural scales, from microstructure (casein micelle and gel particle) to macrostructure (whole gel) (Mellema et al., 2002), but this aspect was not investigated in this study.

In our study, the post-acidification was the same for all yogurts, but the restructuring of the protein network depended on the importance of breakage caused by the mechanical stress of stirring operations. GuénardLampron et al. (2019) explained that the mechanical stress of the sequential stirring operations caused in the rheological and physical properties of stirred yogurt after $1 \mathrm{~d}$ of storage could be related to different gel particle sizes. In the present study, it may be hypothesized
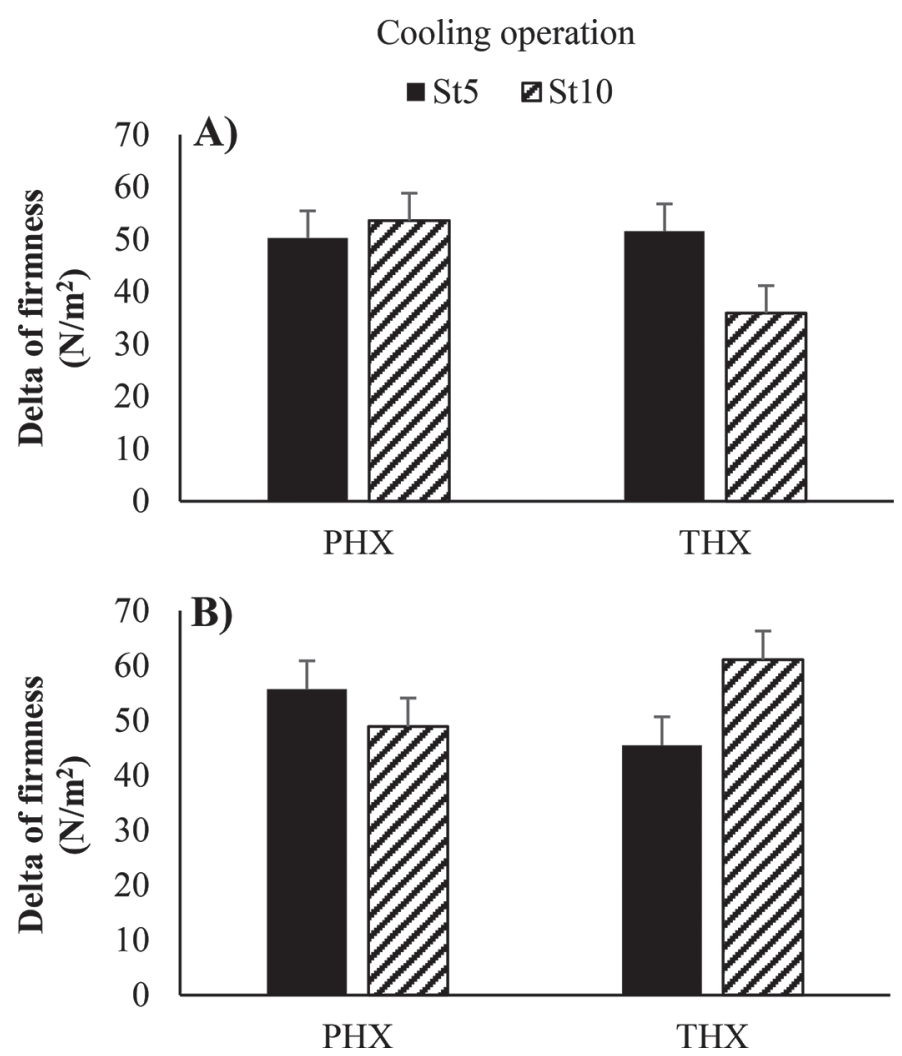

Figure 1. Firmness ( $\Delta$ values) after $22 \mathrm{~d}$ of storage at $4^{\circ} \mathrm{C}$ for stirred yogurts smoothed at (A) $38^{\circ} \mathrm{C}$ or $(B) 20^{\circ} \mathrm{C}$ depending on the cooling system used [plate heat exchanger (PHX) or tubular heat exchanger (THX)] and on stirring time [5 min (St5) or 10 min (St10)]. The error bars represent the standard errors of the mean. that larger gel particles were produced when lower mechanical stress was applied (Sm38 or THX) compared with higher mechanical stress (Sm20 or PHX), and this could modify the protein network restructuring. Puvanenthiran et al. (2002) explained that larger gel particles would be more able to absorb mechanical force without breaking the bonds between particles. This could explain the higher restructuring for lower mechanical stress in the present study. After storage for $13 \mathrm{~d}$, viscosity and consistency values were improved by THX, and flow rate was increased by Sm38. Stirring duration in the yogurt vats (St5 or St10) did not appear to change any of the properties during storage except for firmness when the THX system was used to cool the yogurts. This combined effect of stirring duration and cooling system was not observed with PHX, possibly because the higher mechanical stress induced by this cooling system hid the effect of stirring. However, the intensity of the mechanical stress induced by each combined operation was not evaluated and should be investigated in a future study. The use of combined operations St10 and THX also seemed to counterbalance the higher mechanical stress of smoothing after cooling (Sm20) in terms of firmness. The firmness analysis was probably more sensitive to the combined stirring operations, because this penetration force resistance analysis depends on particle distribution (homogeneity and density), which is affected by the size of the gel particles (Serra et al., 2009). In the present study, syneresis was the only property to be modified by storage time and not by stirring operations. Syneresis during yogurt storage was affected more by post-acidification than by the stirring operations, or post-acidification masked the effects of the stirring operations.

This study demonstrated the effects of the stirring operations (stirring, smoothing, and cooling) on yogurt change during storage. During $22 \mathrm{~d}$ of storage, the effects of the mechanical stress caused by the stirring operations at d 1 disappeared for syneresis values. The reduction in syneresis was probably due to the restructuring of the protein network that occurs during post-acidification. The changes in viscosity and flow time that appeared mostly after $13 \mathrm{~d}$ of storage, and the changes in firmness and consistency that appeared after $22 \mathrm{~d}$, can be explained by the combined effects of the stirring operations and post-acidification. However, yogurt properties were not modified by the same processing step. Combined stirring, smoothing, and cooling operations affected firmness after 22 d. During storage, the cooling system changed viscosity and consistency, whereas smoothing temperature changed flow time. The results from the present study make it possible to determine which combination of operations should be chosen to target specific properties during 
storage for up to $22 \mathrm{~d}$. For example, the use of stirring for 5 min (St5), smoothing at $38^{\circ} \mathrm{C}(\mathrm{Sm} 38)$, and cooling in a tubular heat exchanger (THX) would improve flow time, firmness, viscosity, and consistency during yogurt storage. The next step would be to investigate the relationship between the processing steps (mechanical stress) and changes in the microstructure of the protein network, which modifies the rheological properties of stirred yogurt depending on the post-acidification that occurs during storage.

\section{ACKNOWLEDGMENTS}

This study was funded jointly by the research programs of the Fonds de recherche du Québec-Nature et technologies (Québec City, QC, Canada), Novalait Inc. (Québec City, QC, Canada), and the Ministère de l'Agriculture, des Pêcheries et de l'Alimentation du Québec (MAPAQ; Québec City, QC, Canada). The authors also thank Gaétan Bélanger, Louis-Philippe Desmarchais, and Stefan Grabowski (Saint-Hyacinthe Research and Development Centre, Saint-Hyacinthe, QC, Canada) for their technical assistance with the production of yogurts at the technical scale, as well as Myriam Veilleux-Babin, Annie Caron, and Sophie Turcot (Saint-Hyacinthe Research and Development Centre, Saint-Hyacinthe, QC, Canada) for their technical assistance with the analyses.

\section{REFERENCES}

Arshad, M., M. Paulsson, and P. Dejmek. 1993. Rheology of buildup, breakdown, and rebodying of acid casein gels. J. Dairy Sci. 76:3310-3316. https://doi.org/10.3168/jds.S0022-0302(93)77668 -7 .

Casarotti, S. N., D. A. Monteiro, M. M. S. Moretti, and A. L. B. Penna. 2014. Influence of the combination of probiotic cultures during fermentation and storage of fermented milk. Food Res. Int. 59:67-75. https://doi.org/10.1016/j.foodres.2014.01.068.

Fangary, Y. S., M. Barigou, and J. P. K. Seville. 1999. Simulation of yoghurt flow and prediction of its end-of-process properties using rheological measurements. Food Bioprod Process 77:33-39. https: //doi.org/10.1205/096030899532231.

Guénard-Lampron, V., D. St-Gelais, S. Villeneuve, and S. L. Turgeon. 2019. Individual and sequential effects of stirring, smoothing, and cooling on the rheological properties of nonfat yogurts stirred with a technical scale unit. J. Dairy Sci. 102:190-201. https://doi.org/ $10.3168 /$ jds.2018-14565.

Lee, W. J., and J. A. Lucey. 2006. Impact of gelation conditions and structural breakdown on the physical and sensory properties of stirred yogurts. J. Dairy Sci. 89:2374-2385. https://doi.org/10 .3168/jds.S0022-0302(06)72310-4.

Lee, W. J., and J. A. Lucey. 2010. Formation and physical properties of yogurt. Asian-Australas. J. Anim. Sci. 23:1127-1136. https:// doi.org/10.5713/ajas.2010.r.05.

Lucey, J. A. 2004. Cultured dairy products: An overview of their gelation and texture properties. Int. J. Dairy Technol. 57:77-84. https: //doi.org/10.1111/j.1471-0307.2004.00142.x.

Mellema, M., P. Walstra, J. H. J. van Opheusden, and T. van Vliet. 2002. Effects of structural rearrangements on the rheology of rennet- induced casein particle gels. Adv. Colloid Interface Sci. 98:25-50.

Mokoonlall, A., S. Nöbel, and J. Hinrichs. 2016. Post-processing of fermented milk to stirred products: Reviewing the effects on gel structure. Trends Food Sci. Technol. 54:26-36. https://doi.org/10 $.1016 /$ j.tifs.2016.05.012.

Puvanenthiran, A., R. P. W. Williams, and M. A. Augustin. 2002. Structure and visco-elastic properties of set yoghurt with altered casein to whey protein ratios. Int. Dairy J. 12:383-391. https://doi .org/10.1016/S0958-6946(02)00033-X.

Renan, M., V. Arnoult-Delest, D. Pâquet, G. Brulé, and M. H. Famelart. 2008. Changes in the rheological properties of stirred acid milk gels as induced by the acidification procedure. Dairy Sci. Technol. 88:341-353. https://doi.org/10.1051/dst:2008004.

Renan, M., F. Guyomarc'h, V. Arnoult-Delest, D. Pâquet, G. Brulé, and M. H. Famelart. 2009. Rheological properties of stirred yoghurt as affected by gel $\mathrm{pH}$ on stirring, storage temperature and $\mathrm{pH}$ changes after stirring. Int. Dairy J. 19:142-148. https://doi .org/10.1016/j.idairyj.2008.09.007.

Robinson, R. K., J. A. Lucey, and A. Y. Tamime. 2007. Manufacture of yoghurt. Pages 57-75 in Fermented Milks. A. Y. Tamime, ed. Blackwell Publishing Company, Oxford, UK.

Serra, M., A. J. Trujillo, B. Guamis, and V. Ferragut. 2009. Evaluation of physical properties during storage of set and stirred yogurts made from ultra-high pressure homogenization-treated milk. Food Hydrocoll. 23:89-91. https://doi.org/10.1016/j.foodhyd.2007 .11.015.

Sodini, I., F. Remeuf, S. Haddad, and G. Corrieu. 2004. The relative effect of milk base, starter, and process on yogurt texture: A review. Crit. Rev. Food Sci. Nutr. 44:113-137. https://doi.org/10 .1080/10408690490424793.

Tamime, A. Y., and R. K. Robinson. 1999. Yoghurt: Science and Technology. 2nd ed. CRC Press, Boca Raton, FL/Woodhead Publishing, Cambridge, UK.

Weidendorfer, K., A. Bienias, and J. Hinrichs. 2008. Investigation of the effects of mechanical post-processing with a colloid mill on the texture properties of stirred yogurt. Int. J. Dairy Technol. 61:379384. https://doi.org/10.1111/j.1471-0307.2008.00425.x.

Zoon, P. 2003. Viscosity, smoothness and stability of yogurt as affected by structure and EPS functionality. Pages 280-289 in Fermented Milk. Special Issue 0301. International Dairy Federation, Brussels, Belgium.

\section{ORCIDS}

V. Guénard-Lampron @ https://orcid.org/0000-0003-4428-8918

S. L. Turgeon (ㄱ) https://orcid.org/0000-0003-2448-2844 